\title{
Analyzing the Influence of Neighborhood Development Pattern on Modal Choice
}

\author{
Ali Soltani ${ }^{1}$ and Alireza Shams ${ }^{2}$ \\ ${ }^{1}$ Department of Urban Planning, Shiraz University, Goldasht St., Maaliabad, Shiraz, Iran \\ ${ }^{2}$ Department of Civil Engineering, Clemson University, Clemson, SC, USA
}

Correspondence should be addressed to Ali Soltani; ali_soltani54@yahoo.com

Received 23 September 2016; Accepted 6 December 2016; Published 23 January 2017

Academic Editor: Juan C. Cano

Copyright ( 2017 Ali Soltani and Alireza Shams. This is an open access article distributed under the Creative Commons Attribution License, which permits unrestricted use, distribution, and reproduction in any medium, provided the original work is properly cited.

\begin{abstract}
Although several studies have been undertaken on the association between built environmental characteristics and travel patterns in western societies, the impacts of the local built environment on individuals' travel behavior considering the specific conditions of developing nations have remained largely unknown. Thus, this paper investigates the travel behavior effects of local planning and design in three residential neighborhoods of Shiraz, a city in the southwest of Iran. The data on land use and built environment characteristics were extracted primarily from an existing digital map and GIS, whereas the data on individuals' socioeconomics and their daily travel behavior were purposefully collected using a field questionnaire survey $(n=393)$. A nested logit model (NLM) based on the microeconomic utility concept was then applied to discover the impacts of personal characteristics and built environment factors on the choice mode of the individuals. The results and the associated policy implications can be helpful in defining a strategic agenda for neighborhood design and planning.
\end{abstract}

\section{Introduction}

Due to the uncontrolled urban growth, social, and cultural considerations, Iran is going to be one of the highest car dependent nations in the Middle East and it now has one of the greatest vehicle ownership rates for urban areas in the region. Consequently some undesirable impacts have appeared including overweighting, traffic crashes, air pollution and greenhouse gas production, fuel consumption, and social exclusion $[1,2]$. For instance, it is estimated that one-third of Iranian adults are physically sedentary, and the obvious and hidden costs to the economy of obesity-related diseases in Iran are considerable [3]. Thus, the study of the causal links to transportation and urban planning has a high priority; and as a result, a new endeavor of studies should be looking at how transportation choices are affected by the built environment and then how the planning policies can be amended [4].

This paper explored individuals' travel behavior and its relationship with the observed built environment in three different patterns of urban development of Shiraz metropoli$\tan$ area. The results would be beneficial to help transport/urban planners in their role of evaluating the value of infrastructural development proposals by identifying how health consequences can be included in their evaluation. While most of existing literature is based on the assumption of linear relationship between the built environment attributes and the characteristics of personal travel, this study tried to use more advanced approach; the microeconomic behavioral discrete model is based on the utility maximization as a multivariate technique which can test the nature and magnitude of the direct impacts of multiple interacting factors. This rich technique is particularly well suited to the microscale observational community or population data sets.

The paper is followed by reviewing the background literature and an explanation of the approach selected for the study. The nested logit model (NLM) procedure is then described with a discussion on the significant outcomes of the choice models examined on the data collected throughout the 
case studied area. The paper is ended up with a debate on the findings and drawing some conclusions.

\section{Background}

There is an increasing tendency to find out how built environment and physical form affect travel behavior of residents. This topic was highlighted since 1990s and has inspired a bulk of debates thus far. Review manuscripts have also been published summarizing relevant empirical findings [5-10]. Despite this, several ongoing research efforts aimed at improving the modeling and assessment tools which already applied to measure the effects of these features.

Handy [5] argued that given the motivation to walk, built environment is an exogenous variable that can explain the variance in walking level. While traditional neighborhoods encourage walking for either recreation or shopping, modern designed communities may also achieve the same goal if they provide retail and shops within walking distance. Furthermore, built environment impacts the definite set of modal choices which are realistic for the travelers: built environment plays a key role in defining whether dwellers perceived walking as an available option. Ewing and Cervero [11] have an extensive review of the relative predictive power of various indicators of travel demand. They found that built environments had stronger effects on travel distance than on mode choice, trip generation rates, and other travel-demand outcome measures.

Dieleman et al. [12] analyzed the impacts of built environment and individuals' socioeconomics on travel pattern in the Randstad Holland Region. This study showed that both sets of factors have strong impacts on travel distance and the mode of travel. The physical characteristics of a neighborhood have a sustained effect on modal choice if personal variables are held constant. The residents of outer areas and urban fringe were imposed to make long journeys which made them dependent on private cars or public transit. Furthermore, the built environment showed a significant role in explaining the variation in travel distance by public transit.

Rajamani et al. [13] discovered that land use diversity significantly affects the level of walking for nonwork purposes including recreation and shopping. Furthermore, the proportion of cul-de-sacs and dead-ends is influential in the rate of walking to shopping destinations. Li et al. [14] studied the connection between built environment attributes and physical activity level at both the neighborhood scale and the household scale in an older adult sample. The study found a positive correlation between physical form variables and walking level at the neighborhood scale. At the resident level, the perception of safety for walking and the number of adjacent leisure facilities were directly correlated with the high levels of walking activity.

A microeconomic behavioral modeling study undertaken by Frank et al. [15] found that the locations of residential and employment zones and travel cost were the most significant factors explaining differences in modal choice. Whereas travel time was the most significant variable in predicting modal choice, built environment as the location of living and working was the strongest variable when explaining the frequency of stops taken during a tour.

A comparative study by Næss [16] in Copenhagen found that regional-scale built environment variables had stronger impacts on distance travelled by car than local-scale built environment attributes. The farther the location to the central business district (CBD) area was, the longer the distance travelled. However, microscale neighborhood characteristics showed no significant impact on car travel while controlling for the distance to CBD.

Saelens and Handy [9] reviewed 42 published manuscripts on the interaction between the built environment and travel behavior and attempted to extract factors affecting transport-related walking and leisure-related walking. They discovered that land use diversity and urban density were not linked with the level of walking for transport. In contrast, street network permeability and distance to parks and open spaces were significant explanatory variables of recreational walking. The research by Pan et al. [17] in Shanghai studied the impacts of the spatial structure on the movement patterns of residents. The results showed that, in pedestrian-oriented suburbs, trip-makers travelled shorter distances than trip-makers in other suburbs using the same travel modes. Similar results were found in a research of built environment attributes included density, land use diversity, proximity, and accessibility to public transport with the share of nonmotorized modes of travel in Bogota [18]. Whereas street network density, the proportion of intersection, and permeability were correlated with walking and cycling, other physical factors including density, land use diversity, and accessibility to public transport were not. The reasons for this were less variation in urban density, proximity to transit, and land use mix indices in the studied neighborhoods.

A meta-analysis of the land use travel literature generally showed that travel variables were inelastic with regard to changes in measures of the urban form. None of the built environment variables had an average travel elasticity absolute value larger than 0.4 ; however, the collective impact of a number of such factors on travel might be relatively large. Land use mix, intersection density, and the frequency of trip attractions within walking distance were shown to be related with walking level. Public transit use is correlated with closeness to transit network and street network configuration attributes, with land use mix as a minor factor [19].

The Giles-Corti and Donovan [20] study in West Australia showed that the impact of the physical form attributes on personal activity levels was less than sociodemographic characteristics. On the other hand, the accessibility to green spaces and leisure amenities can induce the higher level of physical activity. Chao and Qing [21], using structural equation models (SEMs), discovered that built environment affects vehicle miles travelled (VMT) and vehicle energy consumption indirectly. Instead, socioeconomic attributes of the household including gender, vehicle ownership, and vehicle properties showed a substantial direct impact on VMT and energy consumption.

According to the points discussed above, the relationship between built environment and travel behavior is more complex than it might be assumed. It is difficult to study the 
causal relationship due to methodological challenges. While a number of studies claim that the relationship is marginal, others emphasize on the need to find better ways to study built environment-travel interactions [9]. Well-designed empirical research must be conducted to derive reliable policies that could direct new development or make interventions in the built environment with the aim of changing travel behavior. A number of issues, including the strength of the evidence, the transferability of findings, the scale of analysis, and the causality of the relationships, must be considered before drawing any conclusions [7]. Therefore, the effect of built environment on travel behavior might be less significant than what the literature has suggested (in which socioeconomics have not been considered). However, this does not mean that urban planning does not help in achieving more sustainable travel patterns. Planning policies can in fact influence travel demand and/or modal choice by managing transport supply and the distribution of land use.

\section{Materials and Methods}

3.1. Study Area. Shiraz as the case study area of this research is the center of Fars province, which is located in the southwest of Iran with a population of 1.9 million based on a report from the Iranian Census Bureau [22]. The city covers an area of 23,000 hectares with a population density of 82 people per hectare. Shiraz is facing traffic problems, especially intraurban traffic crashes due to a considerable increase in motor vehicle ownership and private car users [23]. Moreover, urban development in Shiraz has poorly accommodated the needs of vulnerable road users. Motorized transport modes have been developed whereas the choice of public transport has received less attention.

Despite its semilinear growth pattern, the Shiraz metropolitan area can be broken down into three distinct regions: the Inner Ring, Middle Ring, and Outer Ring. Each of these segments has considerably different populations and built environment structures that eventually affect the travel patterns and, in turn, the traffic challenges in each local area. By dividing the area into separate regions, a detailed analysis is provided revealing the explicit trends within the diverse travel behaviors of the residents of wider Shiraz.

Shiraz's Inner Ring refers to the districts that are between zero and five kilometers from the Shiraz CBD (Imam Hussein Square), which is dominated by administrative/office buildings and a substantial percentage of residential apartments that were built mainly in the past two decades. This ring also encompasses the 300 hectares of the traditional and historic quarters and the monuments and tourist sites. The Middle Ring contains the districts that are situated 5-10 km from the $\mathrm{CBD}$, including the heritage gardens on the west and some brownfield sites and recently renewed estates. This ring has its own sub-CBDs, although it is mainly dependent on Shiraz CBD in terms of business and administrative affairs. The suburbs located in Shiraz's Outer Ring are those that are 10$20 \mathrm{~km}$ away from the CBD. Some have been developed in just the past decade, some are master-planned new communities or are even under construction and some were independent rural and peripheral settlements that have been absorbed into the metropolitan area due to the fast-growing trend of the city. This study selected three neighborhoods from each region: Fakhrabad (Inner Ring), Fazilat (Middle Ring), and Beheshti (Outer Ring). These three areas, in addition, represent three different stages of physical development and their corresponding design patterns. Figure 1 shows the Shiraz metropolitan area and the location and land use distribution of the three studied neighborhoods.

3.2. Built Environment Measure. According to the literature, the physical characteristics of a neighborhood are influential in a resident's choice of mode. In fact, the differences that exist among the three areas explain part of the variance in the travel patterns of the residents. Thus, measuring the physical characteristics of the areas is required before beginning to model travel behavior. Table 1 shows the differences among the three areas in terms of physical characteristics.

3.3. Data. The land use, road network, and population density data were obtained from Shiraz Municipality. Approximately 450 questionnaires were distributed and interviewed based on a random classified approach within the case study areas in March, 2016, and 396 were relatively complete with most of the questions answered. An initial comparison of the sample characteristics to the population features, extracted from the 2011 Shiraz Census data, indicated sound comparability. The database contains 1,262 trip records obtained from the questionnaire survey that characterize travel conducted by individuals who lived in one of the three studied suburbs. Respondents were asked to report all the trips they had in a working day. For example, a respondent may go to work in the morning (trip 1) and then in the evening go to a shop (trip 2 ) and after that return home (trip 3). Different modes may be used in each of these trips. However, the dominant mode (longest distance mode) as the choice was selected for each individual to be included in the model.

3.4. Model Structure and Specification. The Multinomial Logit Model (MNLM) is mostly used because of its comparative simplicity, a potential to add new choices, its ease of estimation, and the wide availability of estimation software. However, concerns about the restrictive assumptions of the MNLM (independent and identical distribution of error terms) and its properties have led to a search for more robust model structures. The Nested Logit Model (NLM) has become widely used in a variety of contexts due to its ability to represent similarities (covariance of error terms) among groups of alternatives. The model, first derived by Ben-Akiva and Lerman in early 1985s [24], is an extension of MNLM which is designed to capture correlations among alternatives.

For the purposes of modeling, a set of discrete choice models were developed in order to explore the role of explanatory variables in explaining the variation in modal choice. The models were all differentiated by travel purpose (work trips versus nonwork trips) because travel patterns will vary depending on the degree to which a trip is discretionary. 

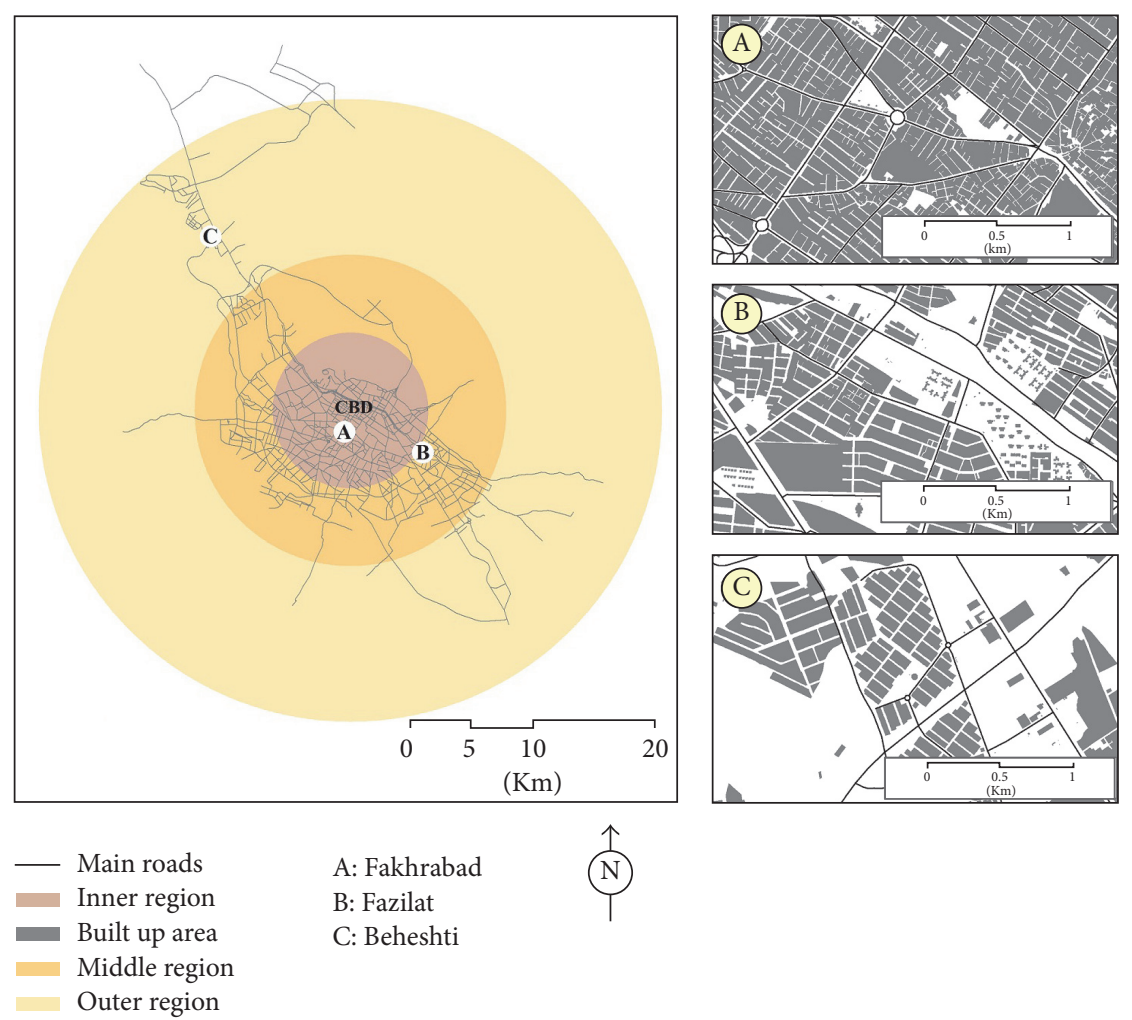
- Main roads
Outer region

Figure 1: Shiraz metropolitan area and the three studied neighborhoods: (A) Inner (Fakhrabad); (B) Middle (Fazilat); (C) Outer (Beheshti).

TABLE 1: Built environment measure for the three studied neighborhoods.

\begin{tabular}{|c|c|c|c|c|}
\hline & $\begin{array}{c}\text { Inner suburb, } \\
\text { Fakhrabad }\end{array}$ & $\begin{array}{c}\text { Middle suburb, } \\
\text { Fazilat }\end{array}$ & $\begin{array}{c}\text { Outer suburb, } \\
\text { Beheshti }\end{array}$ & All suburbs \\
\hline Area (ha) & 84.5 & 102.7 & 92.9 & 280 \\
\hline Population (pp) & 14619 & 14275 & 6317 & 35211 \\
\hline Population density (pp/ha) & 173 & 139 & 68 & 126 \\
\hline Distance to CBD (km) & 2.12 & 5.45 & 17.52 & - \\
\hline Land use mix entropy & 0.63 & 0.34 & 0.21 & 0.39 \\
\hline Nonresidential/residential land use & 0.72 & 0.31 & 0.12 & 0.38 \\
\hline Share of open and green space (percent) & 6.2 & 8.7 & 4.3 & 6.4 \\
\hline Number of intersections & 15 & 6 & 24 & 45 \\
\hline Average census block area $\left(\mathrm{m}^{2}\right)$ & 19,221 & 13,680 & 24,868 & 19,256 \\
\hline Average parcel size $\left(\mathrm{m}^{2}\right)$ & 161 & 343 & 356 & 286 \\
\hline Share of flats and apartments & 31 & 47 & 18 & 32 \\
\hline Number of bus stops & 10 & 5 & 3 & 18 \\
\hline $\begin{array}{l}\text { Number of bus lanes passing through the } \\
\text { area }\end{array}$ & 4 & 2 & 1 & 7 \\
\hline
\end{tabular}

The NLM estimates the probability of an individual selecting an alternative among a choice set. This method is applied to model discrete outcome factors, wherein the log odds of the outcomes are treated as a linear formula of the explanatory factors. Odds ratios in the model represent the effect of one unit of variation in $X$ in the projected odds ratio, with the other factors in the model held constant.

The models use the sociodemographics of the sample households (and individuals) as explanatory factors along with the measures of built environment. The individual is 
TABLE 2: The distribution of choice modes among the three case study suburbs.

\begin{tabular}{lcccccccc}
\hline & $\begin{array}{c}\text { Nonwork } \\
\text { trips, } \\
\text { all suburbs }\end{array}$ & $\begin{array}{c}\text { Nonwork } \\
\text { trips, } \\
\text { inner } \\
\text { suburb }\end{array}$ & $\begin{array}{c}\text { Nonwork } \\
\text { trips, } \\
\text { middle } \\
\text { suburb }\end{array}$ & $\begin{array}{c}\text { Nonwork } \\
\text { trips, } \\
\text { outer } \\
\text { suburb }\end{array}$ & $\begin{array}{c}\text { Work } \\
\text { trips, } \\
\text { all suburbs }\end{array}$ & $\begin{array}{c}\text { Work } \\
\text { trips, } \\
\text { inner } \\
\text { suburb }\end{array}$ & $\begin{array}{c}\text { Work } \\
\text { trips, } \\
\text { middle } \\
\text { suburb }\end{array}$ & $\begin{array}{c}\text { Work } \\
\text { trips, } \\
\text { outer } \\
\text { suburb }\end{array}$ \\
$\begin{array}{c}\text { Total trips, } \\
\text { all suburbs }\end{array}$ \\
\hline $\begin{array}{l}\text { Motorized } \\
\text { (percent) }\end{array}$ & 84.6 & 82.7 & 87.4 & 89.6 & 91.1 & 87.4 & 90.7 & 95.2 \\
$\begin{array}{l}\text { Nonmotorized } \\
\text { (percent) }\end{array}$ & 15.4 & 17.3 & 12.6 & 10.4 & 8.9 & 12.6 & 9.3 & 4.8 \\
$\begin{array}{l}\text { Total number of } \\
\text { cases }\end{array}$ & 712 & 300 & 231 & 171 & 550 & 193 & 143 & 212 \\
$\begin{array}{l}\text { Trips per person } \\
\text { Total number of } \\
\text { respondents }\end{array}$ & 1.81 & 2.12 & 1.97 & 1.31 & 1.4 & 1.36 & 1.22 & 1.62 \\
\hline
\end{tabular}

taken as the unit of analysis to achieve more disaggregated outcomes. The choice set included five alternatives:

(i) Public transport (bus) (C5): available to all individuals

(ii) Taxi/van/school taxi (C4): available to all individuals

(iii) Car use as either driving alone or shared riding (C3): available to all individuals

(iv) Walking and cycling (C2): available to all individuals

(v) Others (C1): including motorcycle and truck that is available to all individuals apart from whom over age 65 and is designated as also being available to those individuals whose travel distance is lower than the maximum distance cycled by an individual

Two nests are considered: (a) nonmotorized trip with one choice: walking and cycling (because the share of cycling is lower than five percent, it is combined with walking) and (b) motorized trip with three choices: car use, taxi/van, public transport, and others. An alternative specific attribute is computed for the nonselected alternatives: travel time. For computing this attribute for each trip, the travel distance was divided by the average speed of the alternative mode.

\section{Results}

4.1. Travel Patterns. The collected data contained 1,262 trip records obtained from the questionnaire survey database that represented travel conducted by individuals who lived in one of the three case study suburbs, which were categorized as inner, middle, and outer. The trip generation based on trip purpose among the suburbs is shown in Table 2. The rate of trip generation for each individual was 3.2 in total: 1.81 for nonwork and 1.40 for work trips, which shows a higher share of nonwork trips such as shopping, leisure, medical/dental, social work, visiting friends or families, and personal business. The other interesting finding is the higher nonwork trip generation for the inner suburb compared to two other neighborhoods (about twice as many as the outer suburb). In contrast, work trip generation for all three areas is similar without a significant difference.
Car dependency rate in Shiraz (about 500 cars per 1000 people) has increased with improvements in economic and welfare conditions, as the car ownership level in this metropolitan area is higher than the average level of wealthy Asian cities such as Singapore (70 cars per 1000 people), Hong Kong (30 cars per 1000 people), and Taipei (175 cars per 1000 people) [25]. Only 12.1 percent of the trips were made by nonmotorized modes of travel, that is, walking and cycling. The rest were undertaken by one of the motorized modes including private car, taxi, and bus. The nonmotorized modes ranged between 17.3 percent for nonwork trips in the inner suburb and 4.8 percent for trips with work purpose in the outer suburb.

The details of modal choice for the three areas are depicted in Figure 2. The dominant mode of travel was the car, either driving alone or sharing rides. This was more typical in the outer suburb and for work trips. The lowest car usage was observed in the inner suburb for nonwork purposes due to its close proximity to diverse destinations, which encourages walking and cycling. The share of trips by public bus for all three suburbs is minor and similar, although the inner suburb has a slightly higher share. Taxi/van is another mode used due to its flexibility and lower cost compared to driving. Again, the inner suburb has a higher share, and this is mostly for nonwork destinations.

4.2. Modeling Result. Different model choice models have been developed with regard to either work or nonwork trip base activity.

The results in Tables 3 and 4 represent the $t$-statistics of the coefficients; since the absolute values of all $t$ statistics are greater than 1.96, all alternative specific constants (ASCs) and the estimated coefficients are significant at 95 percent confidence level.

The models were NLMs, with the five mode alternatives split between two nests to reflect the differences between motorized and nonmotorized forms of transport. The results from the two modal choice models can be found in Tables 3 and 4 . The goodness-of-fit of models at convergence indicated sound fits with adjusted $\rho^{2}$ values of 0.27 (for nonwork trips) and 0.36 (for work trips) compared to the model which has no coefficients. 


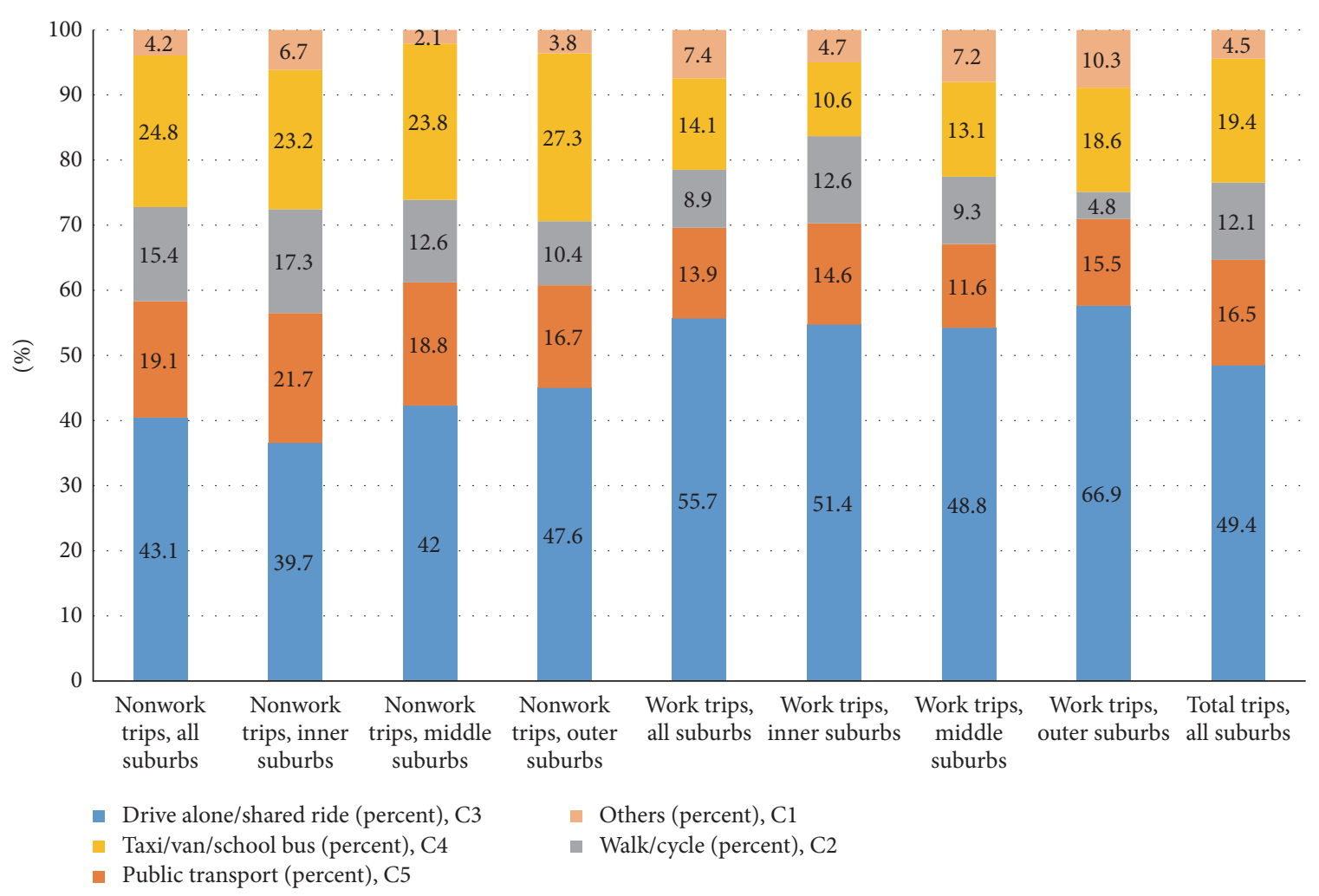

FIgURE 2: Modal choice among the three case study suburbs.

TABLE 3: The nonwork modal choice (all three suburbs).

\begin{tabular}{|c|c|c|}
\hline Variable name, alternative & Coefficients & $t$-statistics \\
\hline \multicolumn{3}{|l|}{ Alternative specific constants (ASCs) } \\
\hline Public transport (C5) & 4.157 & 3.262 \\
\hline Taxi/van/school taxi (C4) & -4.039 & -6.623 \\
\hline Walking (C2) & 0.835 & 3.905 \\
\hline Others $(\mathrm{Cl})$ & 6.759 & 3.161 \\
\hline \multicolumn{3}{|l|}{ Alternative specific attributes (ASAs) } \\
\hline Travel time (min) & -1.607 & -7.538 \\
\hline \multicolumn{3}{|l|}{ Observation specific attributes (OSAs) } \\
\hline Age over 65 years, C5 & 4.389 & 4.880 \\
\hline Female, C4 & 0.017 & 2.350 \\
\hline Person living alone, $\mathrm{C} 2, \mathrm{C} 4$ & -1.061 & -2.382 \\
\hline Number of vehicles, $\mathrm{C} 4$ & -0.421 & -2.235 \\
\hline Number of residents, C5 & 0.519 & 3.954 \\
\hline Number of workers, $\mathrm{C} 4$ & -0.274 & -1.992 \\
\hline Number of workers, C5 & -0.980 & -3.646 \\
\hline Person living alone, $\mathrm{C} 1$ & -1.880 & -3.014 \\
\hline Perceived distance to shopping complex $(\mathrm{km}), \mathrm{C} 1, \mathrm{C} 2$ & -3.559 & -3.779 \\
\hline Perceived distance to school (km), C4 & 0.395 & 2.119 \\
\hline Average floor area (squared meter), C5 & -0.001 & -2.657 \\
\hline Perceived distance to workplace $(\mathrm{km}), \mathrm{C} 2$ & -0.883 & -3.303 \\
\hline Not working, retired, or worked at home, C5 & 4.521 & 3.147 \\
\hline
\end{tabular}

$\chi^{2}=918.683$; degree of freedom $=28$; number of iterations completed $=10$; adjusted $\rho^{2}=0.27$. 
TABLE 4: The work trip modal choice (all three suburbs).

\begin{tabular}{|c|c|c|}
\hline Variable name, alternative & Coefficients & $t$-statistics \\
\hline \multicolumn{3}{|l|}{ Alternative specific constants (ASCs) } \\
\hline Public transport (C5) & 17.373 & 3.889 \\
\hline Taxi/van/school taxi (C4) & -4.371 & -2.976 \\
\hline Walking/cycling (C2) & $-.426 E-01$ & -1.991 \\
\hline Others $(\mathrm{Cl})$ & -2.114 & -4.655 \\
\hline \multicolumn{3}{|l|}{ Alternative specific attributes (ASAs) } \\
\hline Travel time (min) & -0.396 & -1.985 \\
\hline \multicolumn{3}{|l|}{ Observation specific attributes (OSAs) } \\
\hline Number of residents, $\mathrm{C} 4$ & 0.879 & 3.101 \\
\hline Female, C4 & 1.124 & 1.979 \\
\hline Well educated individual, C5 & -13.712 & -2.590 \\
\hline Part time/casual worker, $\mathrm{C} 4$ & 2.373 & 2.846 \\
\hline Management or professional job, $\mathrm{C} 4$ & 11.022 & 3.255 \\
\hline Household income higher than 3 million rials, C5 & -2.053 & -3.655 \\
\hline Vehicles per residence, C5 & -0.698 & -2.469 \\
\hline Single family home, C4 & -0.893 & -1.267 \\
\hline Single family home, C2, C5 & -4.158 & -2.883 \\
\hline Perceived distance to workplace $>5 \mathrm{~km}, \mathrm{C} 2$ & -2.235 & -2.540 \\
\hline Perceived distance to workplace $>5 \mathrm{~km}, \mathrm{C} 4$ & -1.506 & -2.103 \\
\hline Perceived distance to workplace $>5 \mathrm{~km}, \mathrm{C} 5$ & -1.695 & -1.979 \\
\hline
\end{tabular}

( $E-\mathrm{nn}$ is the representative of multiplying by 10 to $-\mathrm{nn}$ power).

$\chi^{2}=469.291$; degree of freedom $=21$; number of iterations completed $=6$; adjusted $\rho^{2}=0.36$.

The values of $t$-statistics of the coefficients and the constants in the two models were all higher than the threshold values of \pm 1.96 (the confidence level of 95 percent), indicating that all ASCs and the coefficient estimates of attributes were significant. Car use as driving alone or shared ride (C3) was considered as the reference choice here due to its higher share.

In both of the developed models, travel time was found to have a negative coefficient, showing that the greater the values of this attribute were, the lower the utility for the trip-maker was. This means that the higher the travel time is, the lower the profit to the traveler is. Alternatively, as this attribute increases for an alternative, the likelihood of selecting that alternative will reduce irrespective of trip mode or purpose. Note that a negative coefficient value of an observationspecific attribute does not necessarily mean that the attribute influences the alternative negatively. Rather, it explains that "the influence of the attribute on the alternative in question is less positive (or perhaps more negative) than the influence of that attribute on the alternative for which the coefficient of the same attribute is used to normalize the other coefficients" [26].

The coefficients of the model show the significance and strength of built environment factors and their potential ability to enhance the explanatory power of the behavioral models. All analyses were performed using LIMDEP ver. 10.0, produced by Econometric Software Inc [27].

4.2.1. Modal Choice Model for Nonwork Trips. The nonwork modal choice model, including the values of the ASCs, the alternative specific attributes (ASAs), and the values of coefficients and their level of significance, is provided in Table 3.

The coefficients of the observation-specific attributes for nonwork travel mode choice in the studied areas show the following: the elders were more likely to catch public transport. This is partly because of the lower ability of the elderly to drive. Females tended to choose a "taxi-van" alternative, perhaps because of its higher security, reliability, and convenience. The higher the number of members who are in a household, the more likely an individual from that household would choose a "public transport" alternative for nonwork travel. The higher the number of workers who are in a household, the less likely an individual from that household would choose a "taxi/van" or "public transport" alternative for nonwork travel. Such an individual probably has sufficient access to a private vehicle. Households with an individual who lived alone were less likely to walk or take other minor modes such as a motorcycle. The greater the number of vehicles that were available, the lower the likelihood that a taxi/van was used. The longer the perceived distance to a shopping center is, the lower the propensity to walk or to ride a bicycle/motorcycle, and so forth, is. The farther the perceived location of a school from home is, the higher the probability of taking a taxi/van to travel there is. The larger the average floor area for a household was, the lower the likelihood that a member of that household used public transport was. The location of a job has a direct effect on choosing a mode for a nonwork purpose, as the longer the distance to the workplace is, the lower the likelihood 
of walking to that nonwork destination is. An individual who was not employed, was retired, or worked at home was more likely to catch public bus to accomplish nonwork travel.

4.2.2. Modal Choice Model for Work Trips. The NLM, including the values of the ASCs, the ASAs, and the values of the coefficients and their significance are provided in Table 4 . The coefficients of the observation-specific attributes for work mode choice in the studied suburbs show the following: the higher the number of members in a household, the more likely an individual from that household would take a taxi/van to travel to work. Females were more likely to catch taxi/van to travel to work than males, perhaps because of its higher reliability and security. Well-educated individuals (with a postsecondary qualification) were less likely to catch public transport to work than other individuals. Individuals who worked in professional or management occupations or worked part time/casual were more likely to choose a "taxi or van" to go to work than individuals with other employment types, perhaps because of having more flexibility in terms of time. Individuals from high-income households (income over 30 million Iranian rials) were less likely to use public transport. This result primarily shows higher car reliance among this social group. As the vehicle number per members increased, the likelihood of selecting to travel by public modes of transport decreased. Residents of single-family households were the least likely to walk or take public transport, and they were less likely to choose "taxi/van" alternatives than residents of other dwelling types. An individual with a perceived job distance of further than five kilometers was more expected to drive alone to work than to be a passenger in a "taxi/van," was less probable to catch public bus, and was least likely to walk to work.

\section{Discussion and Conclusion}

This paper studied the individual travel pattern of the inhabitants of three types of neighborhoods in Shiraz. According to the results of a microeconomic based nested logit model, the following results are achieved.

The residents of the inner suburb have considerably higher trip generation than their counterparts in the outer suburb. For nonwork trips, the trip generation rate was twice that of the outer suburb. However, trip generation for work trips is nearly similar among the inner, middle, and outer suburbs. The inner suburb, with a higher population density, closer distance to the CBD, greater land use diversity, and smaller median block size, exhibits a greater level of walking/cycling and a lower share of car usage, especially for nonwork destinations.

The residents living farther from Shiraz's CBD have a lower tendency to make nonwork trips using nonmotorized alternatives. Furthermore, residing farther from the CBD is linked with more kilometers traveled by car for work purposes; residents who live farther away require longer travel or perhaps they travel longer than they need to. This is because of the centralization of jobs in metropolitan
Shiraz regardless of the general trend toward and measures implemented to decentralize jobs. The evidence shows that the location of employment within each of Iran's large cities is highly concentrated [28]. In other words, the CBD is still the largest activity center, with one in four of Shiraz's employment opportunities and solid employment in the office, specialized and service sectors. Other job centers are present on a smaller scale, in addition to being located in the northern, southern, and northwestern parts of Shiraz. One advantage of the inner communities, for example, Fakhrabad, is having higher access to the job centers in the CBD. The policy of making Shiraz a polycentric city could be useful for modifying the current trend of travel. The literature appears to suggest that workers with jobs in a central area have longer commuting distance than those who work outside the CBD and other subcenters [29]. A study by Veneri [30] in Italy confirms that the creation of a subcenter would increase the likelihood of finding a job close to one's residential area, which in turn enables the reduction of commuting time and distance. In addition, when an individual's job is sited at least five kilometers from residence, the likelihood of using a taxi/van, taking public bus, and walking/cycling is decreased. In fact, in Shiraz, the number of jobs compared with the resident labor force is fairly low; therefore, employees could be challenged to find an employment opportunity close to their residence. This low job-housing ratio may lead to a higher average journey time and distance resulting in the lower shares of walking/ cycling.

Whereas residents of the outer suburb are more dependent on cars, especially for work trips, the inner suburb experienced a higher rate of trip generation. An empirical study from the Puget Sound area in Washington State showed that residents who reduce their travel distance are more likely to take more trips during the day [31]. Land use attributes were shown to be significantly correlated with residents' decisions regarding the kind of shopping trips conducted [32]. Crane [33] argues that residents of areas with closer proximity to shopping destinations may have higher trip generation and higher VMT levels because lower travel cost encourages fewer trips. Thus, households that change their employment location may not necessarily decrease their VMT. Instead of recentralizing working and living zones, it might be better to provide affordable and adequate housing in diversified medium-density communities with reasonable proximity to job centers [34].

As Table 2 shows, the inner suburb has a better mix of land uses and a higher level of population density. The literature indicates that suburbs with greater density and land use diversity generate a higher share of nonmotorized transport. The presence of nonresidential land uses and more access to open and green spaces provides an opportunity for recreational activities such as walking and cycling for leisure [35]. Both land use diversity and urban density could affect the aesthetic dimension of the walking setting and, as correlates of walking, might therefore reflect the collective impact of aesthetics and closeness [9]. As expected, when main facilities and urban services such as schools and shopping centers are located farther away, an individual is more likely to use motorized modes. Throughout the studied areas, the 
farther the shopping center is, the less probable an individual is to use public bus to travel there. Additionally, as expected within the suburbs, the farther the schools are, the lower the likelihood of walking/cycling to school is. This finding is consistent with a study by [21], who found that accessibility shows much better explanatory power than other physical attributes such as urban density and network design and land use diversity measures. Similarly, Lee and Moudon [36] discuss that distance measures to regular daily destinations are more efficient measures than land use entropy and street permeability.

Selecting the best mode of travel means finding the fastest, cheapest, or even most convenient option, depending on the impedance of modal split [37]. This study confirmed that if the impedance is time, then the best mode is that one with the lowest travel time. Similarly, Crane and Crepeau [38] discovered the status of travel time as a cost variable when making a decision whether to involve in an activity. A theoretic handling of the time constraint issue is available in Ettema and Timmermans [39], Gunn [40], and Noland and Polak [41], for example.

Among the social features, it appeared that women in all three suburbs have higher chance to take a taxi/van for nonwork trips and for Iranian women regarding driving. As found by Soltani and Hoseini [42] in a health study in Shiraz, women prefer to exercise at home using private equipment instead of going out. Some reasons could be the lack of sufficient space and amenities such as green space and parks within the neighborhood, in addition to social and cultural barriers, and perceived low safety standards within the neighborhood. The aged (over 65) are more likely to catch public transport for nonwork destinations, as are retired/unemployed individuals due to their decreased ability or willingness to drive and more flexible in-vehicle time [43]. Shigematsu et al. [44] found those aged 66 years and older are more likely to walk instead of using other modes. Consequently, communities are recommended to provide a wide range of destinations close to homes to support walking as a transport option for the elderly. Whereas managers and professional workers are less likely to commute in a taxi/van, part-time/casual workers are likely to do so. Individuals from high-income households, single-home occupants, welleducated people, and individuals from families with a higher number of workers in all three suburbs tend not to take public transport to work destinations. The likelihood of public transport usage decreases if the number of vehicles in the household increases. This is a common issue for many developing countries [45-47].

Fares, quality of service, vehicle ownership, and household income were the most significant factors affecting the frequency of bus use, as found by Paulley et al. [48] in their study of the Britain bus system. In a similar study in the Netherlands, satisfaction with the service quality and proximity to the station showed the strongest impact on rail usage [49]. Within the area of this case study, several discouraging factors are influential: the size of the bus fleet and the coverage of bus network lines and stations are not sufficient to serve all the demands reliably. Bus services are often undermined by traffic congestion, and slow-moving buses are common.
Stations and terminals do not ensure the comfort and safety of passengers to the degree expected by high-income or welleducated people. Under such conditions, buses have a poor image in the minds of such social groups. Enhancing the quality and service frequency and increasing the temporal and spatial coverage of the transit service could make it a more attractive alternative for other age groups.

Throughout the study area the walking and cycling levels are very low; cycling was viewed as fridge mode of transportation, although, within the inner city ring, which is dominated by office buildings, considering all work-related and utilitarian and leisure travel over a 24 -hour period, only 17 percent and 23 percent of the residents walked or cycled for work and nonwork purposes, respectively. Thus, discussions of the potential for the built environment to induce or enable walking/cycling should be undertaken with caution. In fact, interventions in the physical environment may not explicitly change the travel patterns of residents; rather, they may generate conditions that can be expected to work against improved behavior $[9,42]$. The results of study have been retrieved from three suburbs, which are small proportion of Shiraz's population. Therefore, the results are generalizable for different studies to some extent, if they are replicated in further geographical locations where populations with diverse socioeconomic attributes reside. A low variation among the built environment variables in the geographic areas, because of the small sample size, together with less variation within the suburbs cause the built environment measures to be less sensitive to detecting the effect of the built environment on modal choice.

\section{Competing Interests}

The authors declare that they have no competing interests.

\section{References}

[1] M. J. Cohen, "A social problems framework for the critical appraisal of automobility and sustainable systems innovation," Mobilities, vol. 1, no. 1, pp. 23-38, 2006.

[2] F. Atash, "The deterioration of urban environments in developing countries: mitigating the air pollution crisis in Tehran, Iran," Cities, vol. 24, no. 6, pp. 399-409, 2007.

[3] F. Haghighatdoost, N. Sarrafzadegan, N. Mohammadifard, S. Asgary, M. Boshtam, and L. Azadbakht, "Assessing body shape index as a risk predictor for cardiovascular diseases and metabolic syndrome among Iranian adults," Nutrition, vol. 30, no. 6, pp. 636-644, 2014.

[4] H. E. Masoumi, "A theoretical approach to capabilities of the traditional urban form in promoting sustainable transportation," Theoretical and Empirical Researches in Urban Management, vol. 9, no. 1, pp. 44-60, 2014.

[5] S. Handy, "Methodologies for exploring the link between urban form and travel behavior," Transportation Research Part D: Transport and Environment, vol. 1, no. 2, pp. 151-165, 1996.

[6] R. Crane, "The influence of urban form on travel: an interpretive review," Journal of Planning Literature, vol. 15, no. 1, pp. 3-23, 2000. 
[7] D. Stead and S. Marshall, "The relationships between urban form and travel patterns: an international review and evaluation," European Journal of Transport and Infrastructure Research, vol. 1, pp. 113-141, 2001.

[8] P. L. Mokhtarian and X. Cao, "Examining the impacts of residential self-selection on travel behavior: a focus on methodologies," Transportation Research Part B: Methodological, vol. 42, no. 3, pp. 204-228, 2008.

[9] B. E. Saelens and S. L. Handy, "Built environment correlates of walking: a review," Medicine and Science in Sports and Exercise, vol. 40, no. 7, pp. S550-S566, 2008.

[10] W. Bohte, K. Maat, and B. van Wee, "Measuring attitudes in research on residential self-selection and travel behaviour: a review of theories and empirical research," Transport Reviews, vol. 29, no. 3, pp. 325-357, 2009.

[11] R. Ewing and R. Cervero, "Travel and the built environment: a synthesis," Transportation Research Record: Journal of the Transportation Research Board, vol. 1780, pp. 87-114, 2001.

[12] F. M. Dieleman, M. Dijst, and G. Burghouwt, "Urban form and travel behaviour: micro-level household attributes and residential context," Urban Studies, vol. 39, no. 3, pp. 507-527, 2002.

[13] J. Rajamani, C. R. Bhat, S. Handy, G. Knaap, and Y. Song, "Assessing impact of urban form measures on nonwork trip mode choice after controlling for demographic and level-ofservice effects," Transportation Research Record, no. 1831, pp. 158-165, 2003.

[14] F. Li, K. J. Fisher, R. C. Brownson, and M. Bosworth, "Multilevel modelling of built environment characteristics related to neighbourhood walking activity in older adults," Journal of Epidemiology and Community Health, vol. 59, no. 7, pp. 558-564, 2005.

[15] L. Frank, M. Bradley, S. Kavage, J. Chapman, and T. K. Lawton, "Urban form, travel time, and cost relationships with tour complexity and mode choice," Transportation, vol. 35, no. 1, pp. 37-54, 2008.

[16] P. Næss, "Residential location, travel behaviour, and energy use: Hangzhou metropolitan area compared to copenhagen," Indoor and Built Environment, vol. 18, no. 5, pp. 382-395, 2009.

[17] H. Pan, Q. Shen, and M. Zhang, "Influence of urban form on travel behaviour in four neighbourhoods of Shanghai," Urban Studies, vol. 46, no. 2, pp. 275-294, 2009.

[18] R. Cervero, O. L. Sarmiento, E. Jacoby, L. F. Gomez, and A. Neiman, "Influences of built environments on walking and cycling: lessons from Bogotá," International Journal of Sustainable Transportation, vol. 3, no. 4, pp. 203-226, 2009.

[19] R. Ewing and R. Cervero, "Travel and the built environment," Journal of the American Planning Association, vol. 76, no. 3, pp. 265-294, 2010.

[20] B. Giles-Corti and R. J. Donovan, "The relative influence of individual, social and physical environment determinants of physical activity," Social Science and Medicine, vol. 54, no. 12, pp. 1793-1812, 2002.

[21] L. Chao and S. Qing, "An empirical analysis of the influence of urban form on household travel and energy consumption," Computers, Environment and Urban Systems, vol. 35, no. 5, pp. 347-357, 2011.

[22] ICB, Iranian Census Bureau, National Statistics Center, Tehran, Iran, 2016, https://www.amar.org.ir/english/Population-andHousing-Censuses.
[23] A. Soltani and S. Askari, "Analysis of intra-urban traffic accidents using spatiotemporal visualization techniques," Transport and Telecommunication, vol. 15, no. 3, pp. 227-232, 2014.

[24] M. E. Ben-Akiva and S. R. Lerman, Discrete Choice Analysis: Theory and Application to Travel Demand, vol. 9 of MIT Press Series in Transportation Studies, MIT Press, Cambridge, Mass, USA, 1985.

[25] P. Barter, J. Kenworthy, and F. Laube, "Lessons from Asia on sustainable urban transport," in Making Urban Transport Sustainable, N. Low and B. Gleeson, Eds., pp. 252-270, Palgrave Macmillan, Basingstoke, UK, 2003.

[26] F. Primerano and M. Taylor, Towards a Policy Sensitive Accessibility Measure, 2003.

[27] W. H. Greene, LIMDEP Version 10.0-Econometric Modeling Guide, Plainview, New York, NY, USA, 2012.

[28] H. Afrakhteh, "The problems of regional development and border cities: a case study of Zahedan, Iran," Cities, vol. 23, no. 6, pp. 423-432, 2006.

[29] G. Giuliano, Is Jobs-Housing Balance a Transportation Issue? Transportation Research Record, 1991.

[30] P. Veneri, "Urban polycentricity and the costs of commuting: evidence from Italian metropolitan areas," Growth and Change, vol. 41, no. 3, pp. 403-429, 2010.

[31] K. J. Krizek, "Residential relocation and changes in urban travel: does neighborhood-scale urban form matter?" Journal of the American Planning Association, vol. 69, no. 3, pp. 265-281, 2003.

[32] T. Limanond and D. A. Niemeier, "Effect of land use on decisions of shopping tour generation: a case study of three traditional neighborhoods in WA," Transportation, vol. 31, no. 2, pp. 153-181, 2004.

[33] R. Crane, "Cars and drivers in the new suburbs: linking access to travel in neotraditional planning," Journal of the American Planning Association, vol. 62, no. 1, pp. 51-65, 1996.

[34] P. van de Coevering and T. Schwanen, "Re-evaluating the impact of urban form on travel patternsin Europe and NorthAmerica," Transport Policy, vol. 13, no. 3, pp. 229-239, 2006.

[35] J. Feng, "The built environment and active travel: evidence from Nanjing, China," International Journal of Environmental Research and Public Health, vol. 13, article 301, 2016.

[36] C. Lee and A. V. Moudon, "The 3Ds + R: quantifying land use and urban form correlates of walking," Transportation Research Part D: Transport and Environment, vol. 11, no. 3, pp. 204-215, 2006.

[37] A. Soltani and A. Allan, "Analyzing the impacts of microscale urban attributes on travel: evidence from suburban Adelaide, Australia," Journal of Urban Planning and Development, vol. 132, no. 3, pp. 132-137, 2006.

[38] R. Crane and R. Crepeau, "Does neighborhood design influence travel?: a behavioral analysis of travel diary and GIS data," Transportation Research Part D: Transport and Environment, vol. 3, no. 4, pp. 225-238, 1998.

[39] D. Ettema and H. Timmermans, "Costs of travel time uncertainty and benefits of travel time information: conceptual model and numerical examples," Transportation Research Part C: Emerging Technologies, vol. 14, no. 5, pp. 335-350, 2006.

[40] H. Gunn, "Spatial and temporal transferability of relationships between travel demand, trip cost and travel time," Transportation Research Part E: Logistics and Transportation Review, vol. 37, no. 2-3, pp. 163-189, 2001.

[41] R. B. Noland and J. W. Polak, "Travel time variability: a review of theoretical and empirical issues," Transport Reviews, vol. 22, no. 1, pp. 39-54, 2002. 
[42] A. Soltani and S. H. Hoseini, "An analysis of the connection between built environment, physical activity and health: comparing three urban neighbourhoods from Shiraz, Iran," International Journal of Urban Sciences, vol. 18, no. 1, pp. 19-30, 2014.

[43] C. Musselwhite, "Further examinations of mobility in later life and improving health and wellbeing," Journal of Transport \& Health, vol. 2, no. 2, pp. 99-100, 2015.

[44] R. Shigematsu, J. F. Sallis, T. L. Conway et al., "Age differences in the relation of perceived neighborhood environment to walking," Medicine and Science in Sports and Exercise, vol. 41, no. 2, pp. 314-321, 2009.

[45] K. Gwilliam, “Urban transport in developing countries," Transport Reviews, vol. 23, no. 2, pp. 197-216, 2003.

[46] M. Sohail, D. A. C. Maunder, and D. W. J. Miles, "Managing public transport in developing countries: stakeholder perspectives in Dar es Salaam and Faisalabad," International Journal of Transport Management, vol. 2, no. 3-4, pp. 149-160, 2004.

[47] E. A. de Vasconcellos, "Urban change, mobility and transport in São Paulo: three decades, three cities," Transport Policy, vol. 12, no. 2, pp. 91-104, 2005.

[48] N. Paulley, R. Balcombe, R. Mackett et al., "The demand for public transport: the effects of fares, quality of service, income and car ownership," Transport Policy, vol. 13, no. 4, pp. 295-306, 2006.

[49] M. Brons, M. Givoni, and P. Rietveld, "Access to railway stations and its potential in increasing rail use," Transportation Research Part A: Policy and Practice, vol. 43, no. 2, pp. 136-149, 2009. 


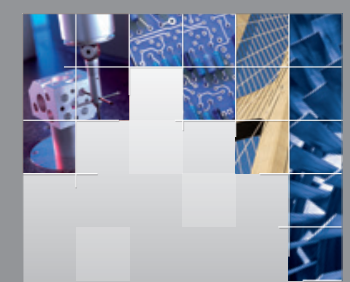

\section{Enfincering}
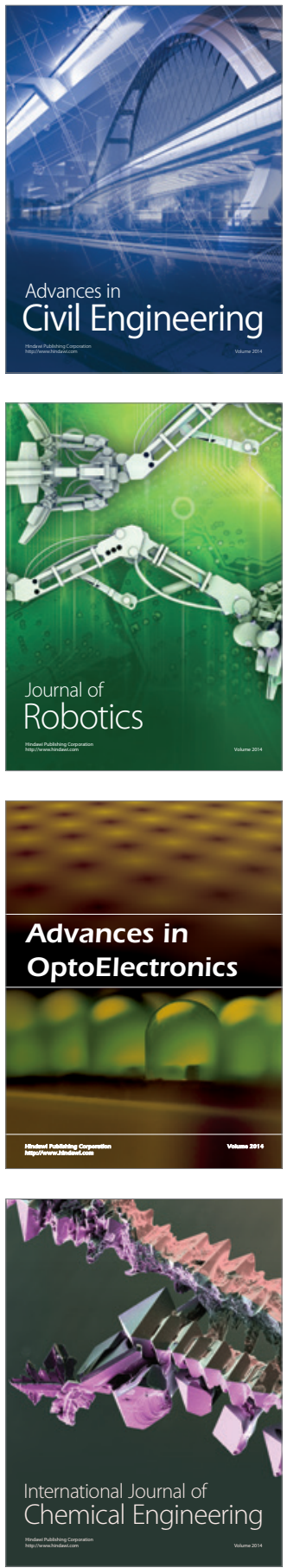

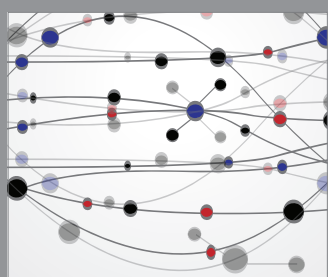

The Scientific World Journal

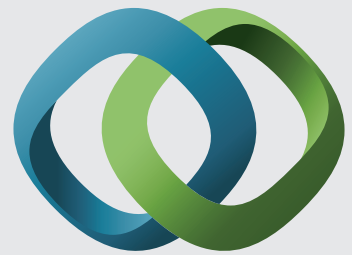

\section{Hindawi}

Submit your manuscripts at

https://www.hindawi.com
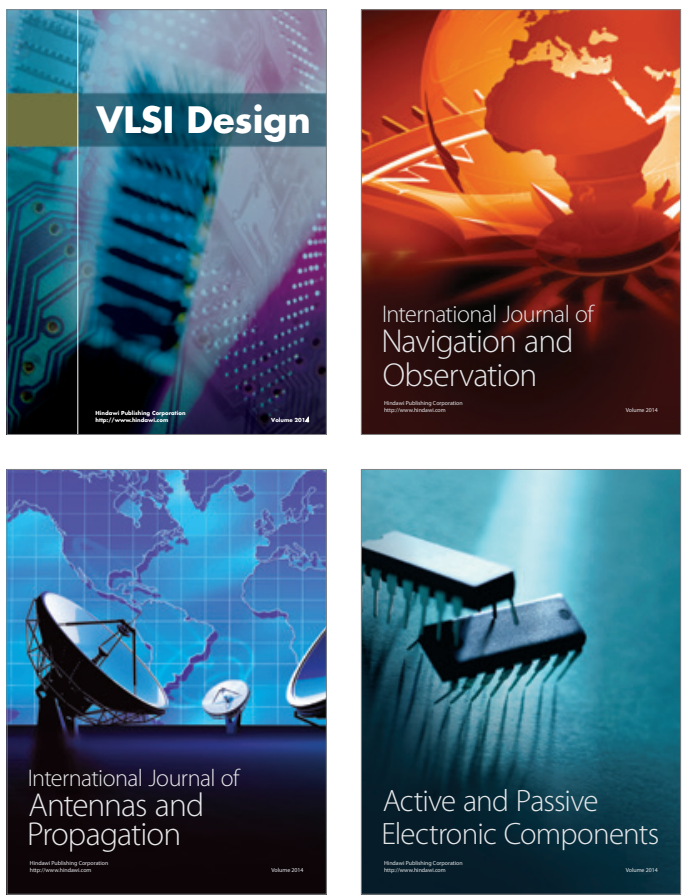
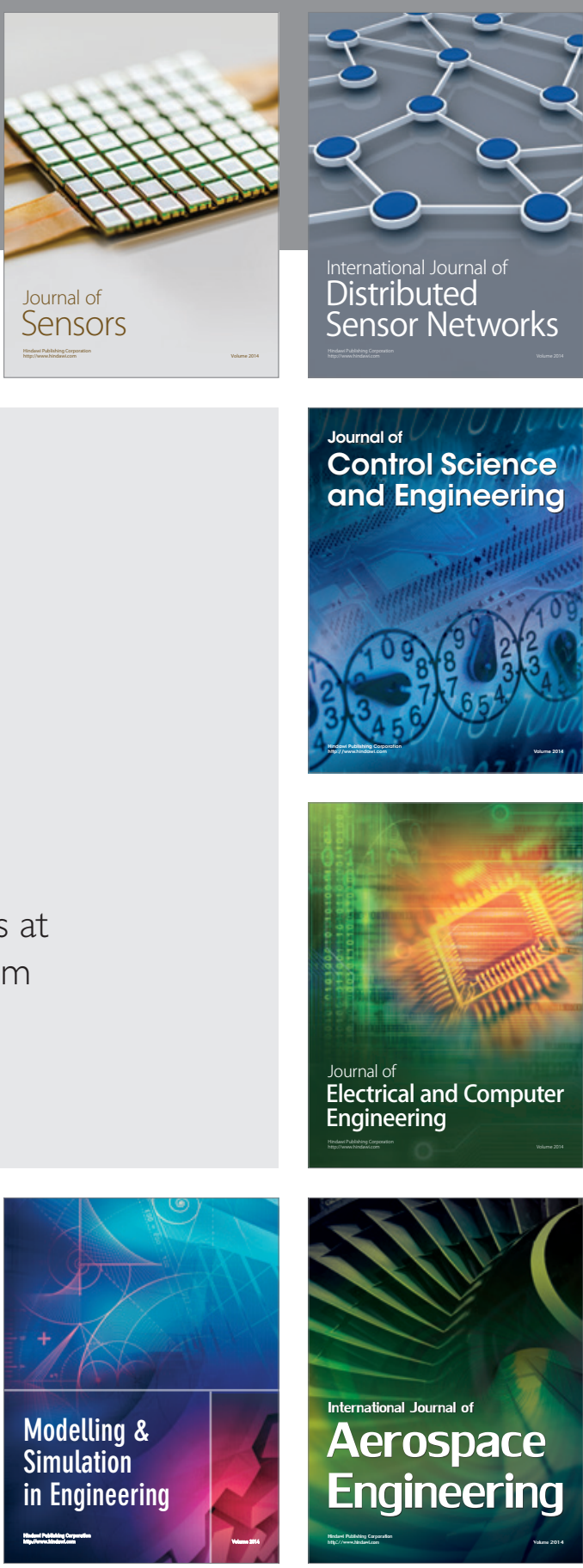

International Journal of

Distributed

Sensor Networks

$-$

Joumal of

Control Science

and Engineering
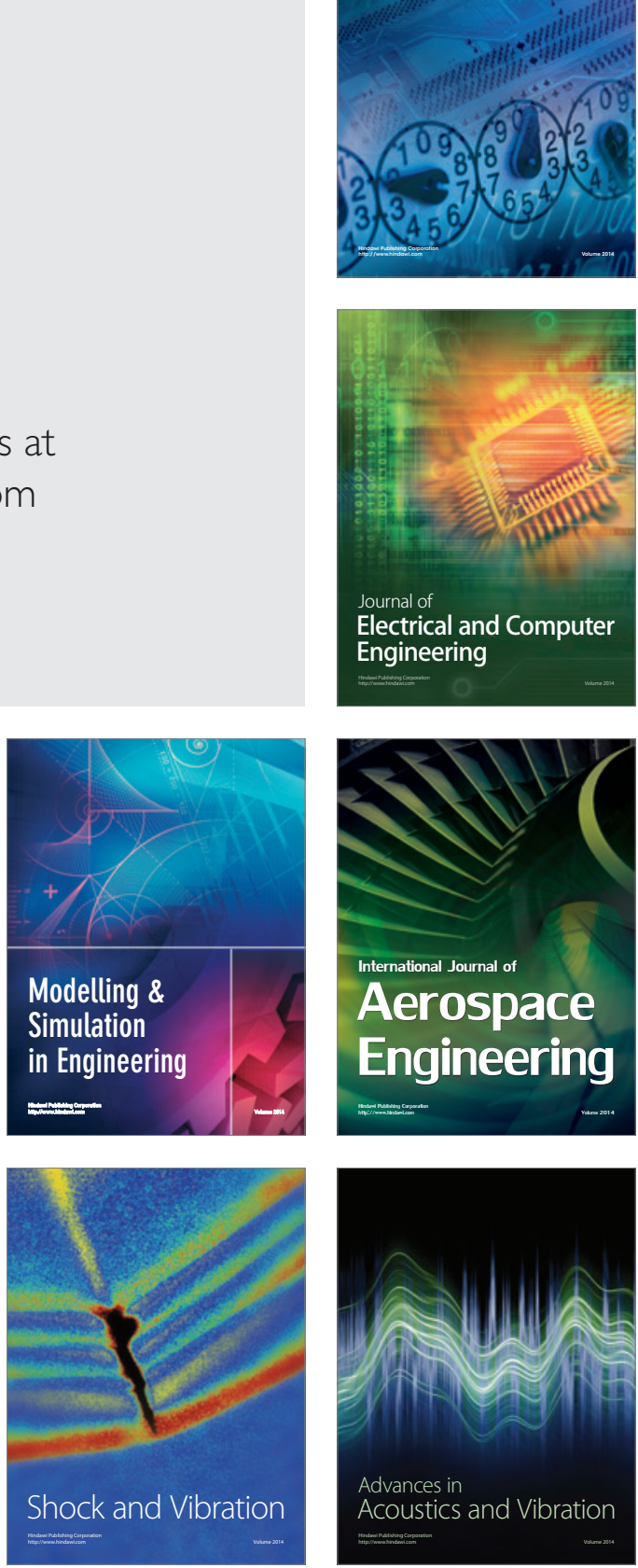